\title{
Facciones liberales en el Estado Soberano de Bolívar: 1860-1868.
}

\author{
Liberal Factions in the Sovereign State Of Bolívar, 1860-1868 \\ Carla Bonell Pagano ${ }^{1}$ \\ Jorge Mejía Turizo ${ }^{2}$ \\ RESUMEN
}

\begin{abstract}
Este artículo examina cómo las facciones políticas hicieron circular sus ideas a través de medios de divulgación como lo fueron hojas sueltas, pasquines y circulares a través de los cuales la sociedad de la época expresaba su opinión acerca de los sucesos coyunturales. Con aquel bagaje ideológico se intentó la movilización del electorado en las épocas preelectorales con el fin de lograr la adhesión de la sociedad a las candidaturas impulsadas por dichas facciones. Así, el enfoque central está dirigido a las facciones liberales del Estado de Bolívar, en especial en cuatro facciones que se desarrollaron entre 1860 y 1868 , teniendo en cuenta que se han denominado como tal por los historiadores para hacer referencia a las divisiones internas de los partidos tradicionales, y para el caso particular del Partido Liberal.
\end{abstract}

Palabras claves: facciones políticas, Partido Liberal, medios de divulgación, movilización del electorado.

\begin{abstract}
This article examines how the political factions circulated their ideas through means of disclosure such as loose sheets, leaflets and circulars through which the society of the time expressed its opinion about the conjunctural events. With that ideological baggage, the mobilization of the electorate in the pre-electoral eras was attempted in

\footnotetext{
1 Historiadora de la universidad del Atlántico, cursando estudios en el programa de Derecho en Noveno semestre de la misma Universidad. Miembro del semillero de investigación Chiovenda adscrito al grupo de investigación Pedro Lafont Pianeta de la Universidad del Atlántico. Correo: carlabonell7253@gmail.com

2 Abogado, Magister en Derecho administrativo, Doctorando en Derecho, Ciencia política y Criminología por la Universidad de Valencia, España. Diplomado en Gestión y Públicas de la Escuela Superior de administración Pública ESAP, Docente de la Universidad del Atlántico y Corporación universitaria Rafael Núñez en investigación Socio jurídica y derecho público, Docente de posgrado en universidad Simón Bolívar y Corporación universitaria Americana. Ex becario del programa jóvenes investigadores e innovadores de Colciencias. Correo mejiaturizo@gmail.com
}

Recibido: 31 de Agosto de 2018

Aprobado: 15 de Noviembre de 2018.
\end{abstract}

Revista Legem, Universidad del Atlántico 4 (2), Julio - Diciembre 2018, pp. 76-112

ISSN: 2346-2787 
order to achieve the adhesion of society to the candidacies promoted by these factions. Thus, the central focus is directed to the liberal factions of the State of Bolivar, especially in four factions that developed between 1860 and 1868, taking into account that they have been denominated as such by the historians to make reference to the internal divisions of the traditional parties, and for the particular case of the Liberal Party

Keywords: political factions, Liberal Party, media, mobilization of the electorate.

\section{Introducción.}

El período que se considera, 1860-1868, se circunscribe en la organización federal que se llevó a cabo en Colombia durante la mayor parte de la segunda mitad del siglo XIX. Durante este período se organizó al país en Estados Soberanos, los cuales gozaban de un régimen constitucional y jurídico propio. Así entonces, cobra existencia el Estado Soberano de Bolívar- lo que actualmente está comprendido por el Departamento de Bolívar, Atlántico y Magdalena- en el cual se lleva a cabo este trabajo.

La dinámica política aquí analizada gira entorno a tres administraciones del Estado en cabeza de Juan José Nieto (1860-1864), Antonio González Carazo (1865-1867) y Manuel Amador Fierro (1868). De este modo, tomamos como punto de referencia las demandas políticas de los actores acerca de las inconsistencias que presentaban cada Administración y la ejecución de políticas públicas con las que el pueblo se mostraba inconforme. Asimismo, fue esencial para la reconstrucción de las facciones y el análisis de su accionar político el período de contiendas electorales para la elección de Presidente del Estado, pues fue en ese interregno en el que las facciones tomaban mayor fisonomía y en el que se conformaban otras nuevas para apoyar una candidatura específica. En periodos posteriores, se han presentado fenómenos de quiebres de estas facciones como lo enseña Vanegas Beltrán (2012) respecto de los años 1930-1945. 
Lo anterior fue posible teniendo en cuenta la dinámica electoral pues a través de ella podemos identificar la cultura política del Estado de Bolívar y el grado de politización de dicha sociedad en tanto que hechos como el fraude y la violencia electoral, así como los mecanismos de movilización del electorado fueron un claro reflejo de la realidad social y política de esta.

Las fuentes primarias escogidas para realizar la investigación fueron las hojas sueltas, pasquines y circulares, los cuales sirvieron como puente de unión entre las ideas y la práctica política; si se prefiere, los medios impresos sirvieron de órgano difusor de las ideas con las que, entre otras cosas- cada candidato cortejaba a su electorado.

Lo antes mencionado lo encontraremos estructurado en el presente artículo de la siguiente manera: un primer subtítulo: "Elecciones, política y opinión pública", en el que hacemos un esbozo de cómo funcionaba el proceso electoral y los vicios que se

presentaban en él- a través de un caso específico de elecciones- los cuales hacían posible el triunfo de algunos candidatos lo que muchas veces generó que se pusiera en tela de juicio la legitimidad de las administraciones y del proceso electoral como tal; un segundo subtítulo: "Faccionalismo político", en el reconstruimos las facciones liberales que se dieron en los distintos momentos del período investigado a través de sus demandas políticas y la dinámica política en general; y por último, las conclusiones a las que hemos llegado basándonos en el caso concreto aquí desarrollado.

\section{Elecciones, política y opinión pública}

Siendo el objetivo principal de esta investigación el estudio del faccionalismo liberal en el Estado de Bolívar para el período de 1860-1868, es menester partir del hecho de que era en los períodos electorales y preelectorales en los que las facciones cobraban mayor fisonomía. El proceso electoral era a través el cual dichas facciones lograban activar toda su maquinaria política respectiva a favor y en contra de los candidatos que se postulaban. 
Debido a las irregularidades que se presentaban constantemente en el proceso electoral, los distintos gobiernos fueron siempre acusados por una parte del pueblo como inconstitucionales e impopulares (Melo, 1995). Cuando hacemos referencia a irregularidades, por ello entiéndase aquellos actos que se consideraban viciaban la transparencia y legitimidad de las elecciones, a saber: la violencia ${ }^{3}$ y el fraude ${ }^{4}$ electoral.

De esta manera, la violencia surgía de la lucha entre miembros de filiaciones partidistas contrarias, y en el caso particular, de la lucha "facciosa". Vale decir que no sólo ser de bandos políticos contrarios generaba la violencia sino más bien que la distinción en la filiación política servía de excusa para resolver (defender y atacar), por las vías de hecho, intereses particulares (Ramírez Bustos, 2002).

Tomamos como ejemplo las elecciones a Concejeros municipales en el Estado de Bolívar en diciembre de 1867. La razón por la cual se toma como ejemplo estas elecciones específicas para explicar la dinámica electoral y la cultura política del Estado de Bolívar es porque según los estudios sobre esta materia se dice que entre más localizada estuviera la elección, más violenta resultaba para cada uno de los protagonistas. Lo anterior quizás pueda explicarse dentro del esquema descentralizador, amplio y autónomo que observaban las localidades, en la que era muy significativo el control del poder en el ámbito local. Además, los cargos que se disputaban, como "los de Concejeros y otros, eran muy importantes dentro de la división política y administrativa del Estado" (Ramírez Bustos, 2002, p. 112).

3Entiéndase por violencia todo tipo de agresión que se pudiera registrar dentro de la dinámica política del Estado de Bolívar y en especial las conductas derivadas de los procesos electorales. La violencia se manifestaba desde el lenguaje bélico-se ventilaba a través de las hojas sueltas, pasquines y hojas circulares aquí utilizadas- hasta la materialización de dichas prácticas, pasando de la agresión verbal a la física.

4Entiéndase por fraude como cualquier práctica para-electoral utilizada para condicionar unos resultados que favorecen a quien hace uso de dichas medidas. Este iba desde compra de votos en pleno día de elecciones hasta la vinculación de agentes del Gobierno en asuntos electorales a favor de determinado candidato. 
Las elecciones aquí registradas hacen referencia a las de Concejo Municipal las cuales "resultaron adversas al círculo liberal" (La Razón, 1867). De esta se dice que el día 15 de diciembre- fecha reglamentada para los escrutinios- se llevaron a cabo de manera agitada, como era costumbre, en tanto que "Ios exaltados liberales (liberticidas) no cesaban de amenazar con que desconocerian el voto popular, ocurriendo a la fuerza, llevando muchos la avilantez hasta pregonar, $q^{\prime}$ arrastrarian en la ruina de los conservadores al Ciudadano Presidente del Estado, si este perseveraba en el intento de dar garantias, por igual, a todos los ciudadanos, sin distincion de colores políticos" ${ }^{\prime \prime}$.

Tal como decíamos párrafos arriba, las elecciones más localizadas como la del Concejo Municipal generaban todo tipo de disturbios y agitaciones. En algunas hojas sueltas se comentaba que dichas elecciones habían sido viciadas por toda clase de fraude y de conductas violentas. Así pues, comentaba el suscrito que habiendo sido testigos de lo ocurrido, debían expresar algunas situaciones que habían viciado las elecciones e intentado cambiar el resultado legítimo de ellas, en tanto que:

"El presidente del jurado se comportó, desde el principio de la sesión, con una parcialidad manifiesta, ajena del carácter favorable que se le atribuia: $2^{\circ}$ Los miembros del jurado se manejaron mal, unos por ignorancia, otros por espiritu de banderia i otros por una meticulosidad exagerada i aun sin fundamento en la mayor parte de la sesión, legitima i excusable al fin de ella" ${ }^{\prime \prime}$.

Con respecto a lo anterior, se explicaba que habiéndose reunido el jurado para llevar a cabo el escrutinio, concurrieron los srs. José de los Santos Miranda y Pedro Rafael Zuñiga, liberales; Antonio Fortich y Benito Beltran, conservadores. Sin embargo, faltaba un miembro para integrar aquel, "i habiendo indicado algunos ciudadanos que

5 Estas expresiones las podemos encontrar en folletos $u$ hojas sueltas publicadas, entre ellas "Apelacion a la opinion pública" (Cartagena, diciembre 22 de 1867), Biblioteca Nacional de Colombia (BNC), Fondo Anselmo Pineda, vol. 978, sin numeración.

6 hace parte de fragmentos recopilados por la Biblioteca Nacional de Colombia, citado en página precedente, "Apelación a la opinion pública" (Cartagena, diciembre 22 de 1867), Biblioteca Nacional de Colombia (BNC), Fondo Anselmo Pineda, vol. 978, sin numeración. 
se llamase al suplente respectivo, Sr. Manuel Ojeda, que se hallaba en la barra, si se habia excusado o no concurria el principal, Sr. José A. López Mora, el Presidente, Señor Miranda, desatendió esta solicitud”. Además, se comentaba que el Presidente del Jurado, el sr. Miranda, días anteriores había admitido la excusa del jurado Sr.Belisario Laza, "sin anuencia de la corporacion que preside, llamando en su reemplazo al Señor Zuñiga, con lo cual se atribuyó funciones propias de esta”.

Por esta actuación, el autor del pasquín preguntaba a la opinión pública: “¿Por qué no se hizo otro tanto con el suplente del Sr. López Mora?" y asimismo respondía: “La razon es mui sencilla: porque aquel sujeto es liberal, como el Sr. Miranda, i a este le subrogaba un conservador, que podria ser un estorbo en el jurado".

El hecho anterior había generado el malestar de los conservadores allí presentes, sin embargo lo ocurrido posteriormente a ello, fue lo que habría de darle sentido a la acusación del suscrito, puesto que el Señor Zuñiga, propuso la nulidad de los registros de los jurados $1^{\circ}$ y $3^{\circ}$, sin abrirlos siquiera, y el jurado aprobó la moción ${ }^{7}$. La nulidad del primero de los registros enunciados, la fundaron, en que faltaban en la carátula las firmas de los jurados respectivos y la del segundo, en que uno de los jurados suscribió la cubierta el 10 y no el 8 del presente, como lo reglamentaba la ley.

Sin embargo, las nulidades de los registros estaban consignadas en el artículo 58 de la ley de la materia de elecciones y el suscrito explicaba que entre ellas no figuraban las faltas referidas. Al final explica que el afán por la nulidad de dichos registros consistía en que el jurado $3^{\circ}$ había dado 15 votos de mayoría al partido conservador. Así, anulando estos registros sólo prevalecerían el escrutinio del jurado $2^{\circ}$ en que los candidatos liberales habían obtenido voto de mayoría, y el del jurado $4^{\circ}$ en que se había empatado la elección.

7 La ley de 7 de marzo de 1860, sobre elecciones, arbitra el medio para averiguar el voto popular, consintiendo en confrontar la pieza anulada con el ejemplar que de ella se deposita en el Concejo Municipal y en caso de que adolezca este del mismo defecto, ocurrir a la boletas para ver si están de acuerdo con el resultado que marcan los registros anulados, en cuyo caso serán válidos. 
El fraude así, tomó distintas modalidades, desde la compra de votos hasta la vinculación de agentes del Gobierno en asuntos electorales, pasando por cualquier vicio en el proceso de escrutinio.

Por otro lado, así como el fraude fue latente en las elecciones de concejeros municipales, también la violencia jugó su parte en ellas. Sobre ello comentaba el autor de la publicación que:

"La barra (liberal) fue perdiendo, poco a poco, la compostura que el acto requeria: primero traspasó la valla que la separaba del jurado, luego invadió todo el salon, en seguida rodeó estrechamente el jurado, i por último, (...) la griteria tomó las proporciones de espantos; hubo exclamaciones unísonas "de abajo el partido conservador" $i$ "viva el partido liberal" i los miembros de dicha corporacion, materialmente sofocados, por una muralla espesa de cuerpos humanos, quedaron convertidos en un grupo de autómatas, idiotizados por las amenazas de una turba fanatizada".

De esta manera, si bien es cierto que los elementos hasta aquí analizados se estiman como restadores de legitimidad del ritmo eleccionario, también lo es que nos permiten analizar el proceso eleccionario como un agente dinámico de la cultura política de la época, así como reflejo de la realidad social y política del Estado de Bolívar.

\section{Faccionalismo político}

En este aparte nos encargaremos de desarrollar el contenido de las distintas hojas sueltas, circulares y pasquines que develan las demandas de personajes influyentes en la política del Estado de Bolívar, a partir de las cuales hemos reconstruido las facciones liberales de dicho Estado entre 1860 y 1868. A través de ello, lograremos establecer cómo se agruparon los facciosos en distintos momentos comprendidos en el período de estudio, así como también alrededor de qué intereses lo hacían y cómo se lograban establecer las distintas facciones. 
Así, la siguiente cita es extraída de una hoja suelta fechada en 1866 durante el gobierno presidencial del Dr. Antonio González Carazo, cabeza de una de las facciones liberales más fuertes de la época (El Gobierno del Estado fuera de la lei" (Cartagena, 21 de diciembre de 1865), Biblioteca Nacional de Colombia (BNC), Fondo Anselmo Pineda, vol. 938, pza. 44.):

"Una de las marcas mas denigrantes de la ominosa administracion Nieto es el cínico abuso que hizo de las expropiaciones, empréstitos forzosos $i$ contribuciones directas. La oposicion caracista clamó contra tanta demasía i una veneracion profunda por la propiedad fue el ariete $q^{\prime}$ usó con mejor éxcito contra sus adversarios. El Doctor Antonio González Carazo fue el adalid que sobresalió, en esa hermosa lucha de la industria con los merodeadores que recojian el fruto que no habian sembrado, redactando bellos artículos, bajo el rubro de "Ataque" $i$ "Defensa".

"A fin de exhibir una muestra del carácter de aquella época lamentable, tomamos la coleccion de El Elector de Bolívar, periódico en que escribia el actual Presidente del estado(...) Rejistramos el impreso i encontramos, como ataque a las expresadas garantías, la lei de 29 de Diciembre de 1862, cuyo artículo $3^{\circ}$, a la letra, dice así: "Ademas de las facultades que se conceden a los Gobernadores por los artículos anteriores, tienen la de contratar empréstitos voluntarios o forzosos en aquellos distritos en que no se haga con puntualidad la remesa del respectivo contigente, cuyos empréstitos serán reintegrados luego que se haya efectuado la remesa".

Lo anterior hace referencia a una hoja suelta con fecha de Diciembre 21 de 1865 en la que el infrascrito Joaquín F. Vélez, haciéndose llamar la voz del pueblo, hacía una denuncia pública sobre la contribución directa que el Gobernador de la provincia de Cartagena- Dr. Antonio Claudio Esquiaqui- con el apoyo del Presidente del EstadoDr. Antonio González Carazo- impuso a los cartageneros.

El hecho es el siguiente: el Gobernador de la provincia de Cartagena y el Presidente del Estado expidieron dos decretos, uno el 18 de diciembre y el otro el 13 de mayo, en 
los que se exigía a los cartageneros una contribución directa de $\$ 15.03761$. Lo anterior era considerado inconstitucional e injusto por varias razones. En primer lugar, el suscrito manifiesta la inconstitucionalidad de los decretos en tanto que "las contribuciones no pueden ser impuestas sino por leyes $i$ decretos, expedidos respectivamente por la Asamblea legislativa i las corporaciones municipales (inciso $5^{\circ}$ del artículo 19 de la Constitucion del Estado)". Así pues, el Poder Ejecutivo y sus agentes no tienen la facultad para estatuir cargas ni obligaciones que vayan en detrimento de la propiedad de los cartageneros como ocurre con el art. $8^{\circ}$ del decreto expedido por el P.E. Dicha facultad corresponde a los distritos que por ley están llamados a la administración de sus rentas. Por otro lado, "la contribución que se autoriza establecer por él a los Gobernadores de provincia, es directa; i tal sistema tributario ha sido completamente excluido, con cierta pompa i solemnidad, de la legislacion de Bolívar", razón por la cual sigue siendo censurable el artículo en cuestión.

El malestar, entre otras cosas, es que según el suscrito, de las disposiciones que tenía la Regeneracion ${ }^{8}$ a cumplir era la ley 11 de Mayo expedida por la Convención para derogar algunas leyes, resoluciones de la Asamblea Legislativa y algunos decretos del Poder Ejecutivo (P.E). Así pues se derogaron las disposiciones que permitían los empréstitos forzosos, las expropiaciones y las contribuciones directas. Pero "es el Doctor González Carazo, caudillo de la reaccion, quien ha vuelto a estampar una de ellas, contribucion directa, en su malhadado decreto de 13 de Mayo", estimaba el suscrito.

Asimismo, éste denunciaba que lo que se buscaba con dicha contribución era abarcar en un sólo acto el cuatrimestre de Julio a Octubre y los dos últimos meses del año. Según esto, ya se han consumado exacciones para cubrir el déficit de julio, agosto y septiembre. Así pues, se hace la pregunta: “¿Qué se han hecho las cantidades

8 Hace referencia al proyecto encabezado por Nieto, Carazo, Santo Domingo Vila, Juan A. de la Espriella, José Araujo, Manuel Cabeza, Manuel Martínez, entre muchos otros personajes de la vida política en el Estado de Bolívar de la revolución de 1859, con la que se buscaba desplazar a los conservadores del poder y liderar los espacios políticos del Estado y del país en general. 
impuestas para cubrir el desfalco de la subvención de ese trimestre?". Lo que se dice es que si se han colectado sólo faltarían $\$ 3,500$ de octubre y no $\$ 8,73230$, que según aseveración del Gobernador, en los considerandos de su decreto, esa es la cantidad que hace falta para saldar el contingente del cuatrimestre anunciado.

Así las cosas, queda en evidencia las inconsistencias de los decretos aquí cuestionados, es decir las razones jurídicas que podían motivar dicha denuncia.

Ahora bien, Joaquín F. Vélez, el infrascrito-del cual hay que decir que era un conservador acérrimo y quien se encargó de revivir en el Estado de Bolívar el partido Conservador- no sólo hace mención de las inconsistencias en los actos del P.E en el ámbito jurídico sino también en lo político, pues dice: "El mismo Doctor González Carazo, no embargante su desenfrenada ambicion de mando ¿no pensaria sincera $i$ lealmente cuando clamaba contra los bajalatos de su digno antecesor?".

Con ello hace referencia a que a pesar de que tiempo atrás fue opositor del gobierno de Nieto entre otras cosas por no consentir las políticas "abusivas" de éste referentes a las contribuciones que según Carazo iba en detrimento del derecho a la propiedad entre otros derechos, durante su gobierno llevó a cabo las mismas políticas.

Lo anterior puede comprobarse en otra hoja suelta, citada en la anterior, en las que el autor- Dr. Antonio González Carazo- dividía en dos partes la información presentada, a saber: la primera titulada "Ataque" en la que anexaba la ley expedida por la Asamblea Legislativa de entonces- año 1864- en la que se decretaba "autorizase al Presidente del Estado para que pueda contratar un empréstito voluntario, o repartido forzosamente por la suma de veinte mil pesos con el objeto de tomar las acciones respectivas en la empresa de navegacion por vapor del canal del Dique". Fragmento este publicado en hoja de circulación "Ataque i defensa de garantias individuales" en la ciudad Cartagena el 16 de mayo de 1864, y hoy se encuentra conservado en la Biblioteca Nacional de Colombia (BNC), Fondo Anselmo Pineda en volumen 938, pza. 26.

Asimismo, se exponía en la segunda parte de la denuncia del Dr. Carazo titulada "Defensa" que: 
"la lei de que me ocupo es inconstitucional, en cuanto dispone el uso de la fuerza para conseguir el empréstito: la propiedad de los ciudadanos de Bolívar está amenazada por esa lei, de ser invertida en una empresa industrial, que aunque beneficios tanjibles i prodijiosos, la fuerza no debe ser nunca el medio de realizarla". Además, agregaba que "obligar un ciudadano de Bolivar a que sea accionista en el proyecto de navegacion del Dique, es obligarlo a ejercer una industria contra su voluntad"( Ataque i defensa de garantías individuales, 1864).

Podemos inferir que las diferencias de gobiernos no eran sustanciales sino de carácter meramente discursivo, en que se hacían denuncias referentes al mal gobierno por expedición de leyes "inconstitucionales" o políticas "abusivas" pero que la oposición al momento de obtener el poder llevaba a cabo las mismas políticas.

Muestra de lo anterior es lo que el suscrito de la pieza "El Gobierno del Estado fuera de la lei" escribía:

"Manifestarémos, empero, implorando el testimonio de nuestros lectores de la ciudad, que los contribuyentes liberales se hallan notablemente mejorados en proporcion con los que son conservadores. ¿Se quiere alguna prueba de hasta dónde se ha llevado el espíritu de partido? Sépase, pues, que conservadores de mediana fortuna, amigos fervorosos del Gobierno(...), tienen un 50 i aun un 75 por ciento mas q' capitalistas liberales de una lista de contribuyentes liberales al lado de otra de conservadores, procurando el parangon hasta donde fuese dable, se comprenderia fácilmente que el señor Gobernador, o mejor dicho, el Doctor González Carazo (porque es bien sabido que es el autor del reparto), al formar la distribución se había dicho: a los nuestros con razon o sin ella”. 
A este punto es importante mencionar que las denuncias hasta ahora presentadas y las que siguen, encuentran su razón de ser, en gran medida, en la lucha partidista de la época. Dichas luchas no sólo ocurrían entre partido liberal y conservador sino entre las facciones del partido liberal, como se había hecho mención anteriormente.

Joaquín F. Vélez, hacía parte del partido conservador de Cartagena mientras que González Carazo habría sido el candidato del partido liberal que ganó las elecciones de Presidente del Estado para el año de 1865, sucesor así de Juan José Nieto, quien habría pertenecido de igual manera al partido liberal pero desde una facción diferente y opuesta a la de Antonio González Carazo. Así pues, teniendo en cuenta lo anterior entiéndase que la lucha facciosa en la década de los sesenta en el siglo XIX para el caso del Estado Soberano de Bolívar comenzó a las cabezas de los personajes antes mencionados: Juan José Nieto y Antonio González Carazo, con sus facciones denominadas nietistas y caracistas, respectivamente.

En consonancia con lo anterior, consultamos un pasquín en el que, por ser pasquín, no se conoce el nombre del autor pero por el discurso entendemos que es la defensa a los ataques contra Carazo, así pues deducimos que quien escribe es un liberal.

Ahora bien, en este pasquín el autor menciona a "Véritas" otro anónimo que escribió una serie de pasquines en defensa del Ciudadano Presidente Antonio González Carazo y frente a ello dice: "El (Véritas) encuentra virtud $i$ fuerza de voluntad incontrastable, en la tarea de fundar un sistema tributario, basado en la equidad, que hace que la ciudad pague como ciudad, el miserable villorrio como miserable que es, (...) $i$ en fin, que el rico pague como rico, i el pobre como pobre: i no como es costumbre i mala usanza entre jentes de esa ralea, en que para que todo marche bien, es necesario que el infeliz pague la justicia que se administra al poderoso" (Cual antes, discutamos, 1866).

Asimismo, el autor expresaba que la razón por la cual los conservadores se oponían al sistema tributario propuesto por Carazo era que "ellos son los hombres de los privilejios i monopolios, i es claro que toda idea que tienda a fundar el equilibrio social, basándola en la igualdad, será combatida por esos nuevos sicofantas, que no sueñan 
sino en comprimir con el pie la garganta de ese jigante a quien llaman pueblo" (Cual antes, discutamos, 1866)..

De igual manera, escribía "Un contribuyente" que "Ahora aconseja, el Señor Vélez la resistencia brutal al pago de una contribucion legal, justa, i cuya honrada inversion no ha osado él mismo poner en duda. I al mismo tiempo que lanza al pueblo esa idea, a la primera insinuación del Colector paga su cuota de contribucion (\$16)"9.

Así pues, todas estas discusiones servían como cortina de humo a las verdaderas luchas políticas entre partidos y facciones de partidos que buscaban detentar el poder y perpetuarse en él. Muestra de ello es que más adelante en el pasquín "Cual antes, discutamos" escribía el anónimo: "La verdad es, que con el medio que han adoptado, $i$ que aconsejan a sus adeptos, se proponen embarazar la marcha de la Administracion pública; i creen que así se hará necesaria su presencia en el Gobierno; pero que se desilucionen, porque mientras permanezcan adheridos a su pasado (...) cualquiera tentativa reaccionaria en su favor, no haría sino hundirlos para siempre en la nada, de donde incautamente fueron sacados por la oleada restauradora de 1864" ( Cual antes, discutamos, 1866 pza 51).

En ese orden de ideas, lo que se están disputando los partidos y las facciones liberales es la próxima administración que se avecina, pues desde la revolución de 1859 los liberales habrían ostentado el poder en el Estado Soberano de Bolívar. Cabe mencionar que las piezas hasta aquí citadas están fechadas entre Diciembre de 1865 y Enero de 1866, siendo ya un año del Gobierno de Carazo, luego de cuatro años de gobierno de Juan José Nieto. De esta manera, vale decir que todos estos enfrentamientos partidistas fueron comunes durante todo el período en estudio.

Como muestra de lo anterior, en un pasquín - fechado en enero 16 de 1865- escrito por "Muchos conservadores" explicaban la situación antes descrita, a saber: 
"Después de la revolucion de 1859, encabezada en Cartajena por el señor Antonio González Carazo, i presidida en seguida por el señor Juan José Nieto, que dio por resultado la muerte del partido conservador en este Estado, todo habia quedado en calma; solo el partido triunfante tenia derecho a victorear i figurar en el Estado. Ese partido que se adueñó del poder se dividió al fin.-La fraccion que encabezó la oposicion declaró guerra a muerte a los hombres encargados del Gobierno"10.

Sea dicho de paso que, si bien es cierto que después de 1859 el poder fue detentado por el Partido Liberal en la cabeza de Juan José Nieto, las otras aseveraciones del autor no pueden ser tomadas como ciertas pues quien o quienes escriben son conservadores que buscaban mostrar una imagen conveniente, con el fin de ganar adeptos para el partido.

Asimismo, escribían los autores que:

"Ese partido (liberal) que se adueñó del poder se dividió al fin._La fraccion que encabezó la oposicion declaró guerra a muerte a los hombres encargados del Gobierno; i en todos sus periódicos, en todos sus escritos, repletos de insultos $i$ acusaciones, se desafiaban sin cesar, tomando siempre como pretesto la falta de garantias, la tirania con que se manejaban, los abusos estraordinarios del poder" (Al publico, 1865, pza 41)

Aquí cuando se menciona una facción de oposición al gobierno, se hace referencia a la facción encabezada por el Dr. Antonio González Carazo y la facción del Gobierno, a la encabezada para entonces por el candidato Juan Antonio de la Espriella.

Al respecto, decía el autor del pasquín en cuestión: "Llegó la época de la eleccion de Presidente, fijándose el Gobierno en el señor Juan Antonio de la Espriella, i la 
oposicion, compuesta de conservadores i liberales, en el señor Antonio Gonzalez Carazo".

Lo anterior hace parte de una publicación fechada para enero de 1865, es decir terminado el período presidencial de Juan José Nieto y en plena contienda electoral para disputarse el cargo de Presidente del Estado en el período siguiente.

Asimismo, el autor decía: "En todo el Estado se disputaba la eleccion, estando la mayoria por el señor Antonio González Carazo, que, segun él i sus compañeros, daria garantías i salvaria el pais de los males que le amenazaban”. Asimismo, explicaba que en las elecciones se habían presentado disturbios que habían llevado a los ciudadanos a armarse y que fue así que "triunfó la opinion uniforme de la fraccion liberal oposicionista i la del partido conservador engañada” (Al publico, 1865, pza 41) .

Para efectos de la reconstrucción de las facciones liberales en el Estado de Bolívar, es menester mostrar cómo fue la contienda electoral entre Carazo y Espriella,y así quiénes y cómo hicieron posible la lucha facciosa.

Es importante mencionar también que la estructura de las publicaciones que solían presentarse en época preelectoral y electoral solían ser así: una parte en la que se explicaba cuál era el motivo de la publicación, otra en la que se dejaba por sentado el apoyo a una candidatura específica y por último injurias o denuestos en contra de la candidatura de la oposición.

En consonancia, en una publicación fechada en Agosto de 1864, decía el suscrito, Pablo Cañaveras, que: "En este asunto es bien conocida mi opinion, i no es de ahora que lanzé al público la candidatura del señor Juan Antonio De La Espriella como la única que sostendría por todos los medios lícitos i honrosos". Sin embargo, he aquí la parte importante de la publicación pues deja claro el autor que el apoyo a la candidatura de de la Espriella no es per se sino que en 1859 tuvo el honor de ocupar un asiento en la notable Asamblea que constituyó al Estado y "allí manifesté que despues del Jeneral Juan José Nieto, el hombre llamado a rejir los destinos de mi patria era el Señor Juan Antonio de la Espriella, i consecuente con mis creencias, di el 
voto como lejislador para Presidente interino a favor del Ciudadano Jeneral Nieto" ( $A$ los liberales, 1864, pza 29).

Asimismo, decía el autor que "tuve pues la satisfaccion de ser uno de los Diputados que recibieran la promesa constitucional del primer Presidente lejítimo del Estado $i$ trabajé con el mayor entusiasmo en la eleccion popular del mismo Ciudadano" y además "volví a tener satisfaccion de formar parte del cuerpo lejislativo en 1860 i 1861 ante quien se posesionó de la primera Majistratura, por eleccion popular, el citado Jeneral Nieto, Primer Jefe de la revolucion del 26 de Julio de 1859" (A los liberales, 1864, pza 29)..

De esta manera, nos damos cuenta que el candidato Juan Antonio de la Espriella tuvo el respaldo de los que en su momento se consideraron nietistas. No ocurrió con todos, como veremos más adelante, pero sí con un número importante.

En otra publicación fechada en Agosto de 1864, el suscrito Francisco P. Pacheco expresaba que el señor Simón Alandete (conservador) se le había acercado con una lista en la que indicaba como candidato al Sr. González Carazo y éste no vio inconveniente en firmar dicha lista apoyando a la candidatura en mención. Sin embargo, escribía que más tarde se aseguraba que dicha candidatura estaba apoyada por los conservadores cosa que hizo retractar su apoyo a ésta.

El sr. Francisco P. Pacheco, aseguraba que no era de aquellos que preferían a sus enemigos y "verdugos-conservadores" antes que a los hombres del Gobierno porque

"al Jefe que gobierna el Estado lo he sostenido, con mi voto, como ciudadano, i con un fusil en el campo de batalla contra los enemigos, desde el 26 de Julio de 1859 hasta su terminacion, i jamas traicionaré la obra de mis esfuerzos i de mis convicciones, por la que he pasado muchos trabajos $i$ penalides, por caprichos o cuestiones personales, ni mucho ménos con ayuda de los enemigos". Por tanto, sentenciaba: "mi voto i mis esfuerzos serán por el candidto liberal Jeneral Juan A. De La Espriella" (A los liberales, 1864, pza 31). 
Podemos ver que si bien el suscrito estaba decidido a apoyar a Carazo por "conocer los méritos del Candidato" (A los liberales, 1864, pza 31), el hecho de haber apoyado a Juan José Nieto en la empresa de la revolución y tener ese tipo de relación con él fue fundamental para que éste decidiera dar el apoyo a Juan A. De La Espriella.

Es importante tener en cuenta que las relaciones con personajes públicos que por sus cargos movilizaban tantas personas fue fundamental para la conformación de las distintas facciones. Muestra de lo anterior es lo que expresaban "Unos camaradas" como firmaban- en un pasquín titulado "Aclaratoria" con fecha de $1^{\circ}$ de Septiembre de 1864, a saber: "El Coronel Manuel González Carazo, Comandante del Batallon Glorioso, trabaja en este Cuerpo con la mayor libertad en favor de su hermano el Doctor Carazo, candidato de la oposicion, i nadie le hace una observacion" ( "Aclaratoria", septiembre $1^{\circ}$ de 1864 , pza. 32.)

Así como el hermano del candidato Antonio González Carazo hacía uso de su poder dentro del Ejército, también ocurrió lo mismo con el candidato del Gobierno, Juan A. De La Espriella, a saber:"Si el Ciudadano Jeneral Nieto hiciera como se dice, quién podría disputarle su prestijio con los soldados?". Así pues, el éxito del fenómeno de adhesión consistía entre otras cosas en la reputación de la imagen a quien siguen los posibles adeptos. Por ejemplo, en la misma publicación, los autores agregaban: "El Jeneral Nieto trata, tanto en guarnicion como en campaña, a los soldados como si fueran sus hijos, $i$ siempre los ha conducido a la victoria: prueba, que cuando sale todos se quieren ir con el. Luego si el Jeneral Nieto dijera: 'Ea, muchachos, vamos a votar por el Señor Espriella' quién se le paraba éntonces?"

De igual manera, la difamación fue un elemento esencial para el fenómeno de retractación, durante las contiendas electorales, para aquellos que estuviesen decididos a apoyar al candidato opuesto. Sobre ello, se decía en el pasquín: "Hai reputaciones que ninguno puede combatir. El Doctor Carazo trata a todo el mundo mal, i a los soldados peor, i siempre los ha llevado a la derrota".

Los fenómenos de adhesión y retractación de los facciosos fueron posibles por la estructura de los medios de movilización del electorado como fueron los pasquines y 
hojas sueltas. Dichos fenómenos se basaron en tres aspectos: la reputación del candidato (haciendo uso de la difamación), la violencia electoral (ya como partido o facción) y el fraude (en materia electoral y otros).

Verbigracia, hay una publicación titulada "Capitulo en que se demuestra que la verdadera superchería está de parte de los gobiernistas, o sea del Presidente del Estado i de su Srio. Jeneral" en el que "Varios carazistas" -el suscrito- afirman que el fraude lo están cometiendo los gobiernistas. La anterior es la respuesta a una otra publicación titulada "Superchería de los Carazistas" en la que se dice que entre el Sr. Juan Antonio De La Espriella y la "Sociedad Democrática" se había celebrado "una transaccion" por virtud de la cual el Sr. Espriella renunciaría a su candidatura siempre que no se examinaran sus cuentas.

Cabe aclarar que "La Sociedad Democrática" aquí involucrada fue una sociedad de carazistas quienes llevaban a cabo la campaña eleccionaria del Dr. Carazo, como bien se expresa en "Noticias de Barranquilla". Por tal razón, el suscrito de la pimera publicación en mención muestra indignación, pues involucra la Sociedad Democrática, por ende se le da un giro al discurso recayendo esta vez el peso de la opinión pública sobre el Sr. Espriella, a saber (Noticias de Barranquilla" (Cartagena, noviembre 3 de 1864), Biblioteca Nacional de Colombia (BNC), Fondo Anselmo Pineda, vol. 978, pza. 35):

"la oposicion le ha dicho al Señor Espriella verdades mui amargas; Io ha descrito mas de una vez con los colores que le corresponden; no tiene, ni puede tener confianza ninguna en hombres de su carácter $i$ antecedentes, $i$ seria necesario suponernos mui imbéciles para que se nos creyera capaces de fiarnos en transacciones, aun en el caso de que estas fueran posibles, con entes semejantes"11. 
Además, por ser Nieto el impulsor principal de la candidatura de Espriella otra estrategia para debilitar ésta fue desvirtuando la imagen de Nieto frente a todos los ciudadanos que en algún momento votaron por él para Presidente del Estado. Al respecto el autor expresaba: "nosotros, los miembros de la digna oposicion en este Estado, trabajamos i nos oponemos a las miras nefandas de los Señores, Nieto $i$ Espriella, en obsequio de los principios republicanos que aquellos pretenden hollar".

De esta manera, los carazistas no sólo lograrían ganar los adeptos de Espriella sino también los espriellistas que fueron nietistas en su momento. Muestra de esto es que en la misma publicación se habla sobre el cambio en la posición del general Manuel Martínez, a saber: "Respecto del Jeneral Manuel Martínez, nada hemos dicho que pueda ofender su honor. Él, así como los valientes momileros i como todos los hombres que estiman su dignidad i su propia reputacion, bien ha podido pensar hoi de una manera distinta de la de ayer i decirlo con franqueza, lo cual no será nunca desdoroso para ningun hombre de bien". Lo que se da a entender es que el general Martínez quien en su momento estuvo a favor de los "gobiernistas" ahora ha decidido hacer parte de los carazistas pues, el suscrito agregaba: "Nosotros lo conocemos y lo aceptarémos con mucho gusto; pero no hemos empleado ni emplearémos medios infames i halagadores para atraerlo a nuestro partido.-Ningun hombre es necesario."

Lo cierto es que después de la guerra del 26 de Julio de 1859 contra el gobierno de Mariano Ospina Rodríguez (1857-1861), recrudecida la cosa política por los enfrentamientos entre federalistas y centralistas, los liberales en el Estado Soberano de Bolívar habían sido representados por Juan José Nieto quien encabezó dicha guerra y en general el proyecto del federalismo desde la primera mitad del siglo XIX (Fals Borda, 1981). Con él habrían emprendido la revolución personajes como Antonio González Carazo, quien habría hecho parte de los Ejércitos comandados por Nieto para la revolución del 59 y otras empresas; Ramón Santodomingo Vila, soldadoprefecto y luego Mayor del "Batallón Glorioso"; Juan Rives, José Araujo, Gobernador de Cartagena luego del triunfo de la revolución del 59; Manuel Martínez; Manuel Cabeza; Manuel Pereira Plata, Coronel de la milicia del Estado de Bolívar y 
comandante general de los departamentos del Sinú y Corozal ${ }^{12}$; Juan Antonio de la Espriella, entre otros, quienes habrían hecho parte de la junta revolucionaria para llevar a cabo la guerra contra el gobierno general. (Jose Araujo Gobernador de Cartajena", noviembre 4 de 1859).

Así como el general Manuel Martínez, otros servidores de Nieto terminaron siendo opositores de él años posteriores a la guerra del 59.

Como muestra de lo anterior, en una hoja suelta- fechada en Diciembre de 1864- en que el suscrito Federico Núñez hablaba sobre un acontecimiento el 11 de Noviembre de 1864 en que "el Pueblo de Cartajena (...), se sublevo altivo i enérjico contra unos gobernantes refractarios que por mas de cuatro años le hicieron sumir los momentos de la ignominiosa tiranía doméstica, hasta el estremo inaudito de pretender imponerle, por medio del fraude $i$ de la superchería, un sucesor en la Presidencia del Estado"13, haciendo con esto referencia al gobierno que, como dijimos en el párrafo anterior, dirigió Juan José Nieto de 1860 a 1864 después de haber librado la revolución de1859.

Sin embargo, no fueron personajes ajenos a esta historia quienes hicieron parte de la sublevación contra el gobierno de Nieto, pues el autor expresaba que: "Con esas armas se han organizado tres ejércitos de voluntarios, que obran activamente: en el Sinú, uno al mando del Jeneral Manuel Martínez; en Sabanas, otro al mando del Jeneral Ramon Santo Domingo Vila; i en Barranquilla, el último i mas formidable(...) al mando del Teniente Coronel Manuel de la Cruz Cordovez, contándose en el número de sus valientes jefes $i$ oficiales, el intrépido i abnegado Ciudadano Félix Bárrios" ( Alocucio...n, 1864) .

12 Es pertinente resaltar el documento conservado en la Biblioteca Nacional de Colombia (BNC) en el que se describen estos acontecimientos con el nombre de "Manuel Pereira Plata. Coronel de la milicia de Esatdo de Bolívar i Comandante jeneral delos departamentos del Sinú i Corozal" (Chinú, 3 de diciembre de 1859), Biblioteca Nacional de Colombia (BNC), Fondo Anselmo Pineda, vol. 978, pza. 14.

13 Fragmento recogido en "Alocucion del Gobernador de la Provincia, a los habitantes de Cartajena" (Cartagena, 12 de diciembre de 1864), BNC, Fondo Anselmo Pineda, vol. 978, pza. 40. 
Las causas por las cuales el general Manuel Martínez cambió de facción no son muy claras pues en ninguna publicación explica éste las razones, pero sí queda claro que si bien es cierto que acompañó al Sr. Juan José Nieto en la empresa de la revoución a comienzos de la década de los sesenta, también lo es que años más tarde se opuso a él y formó parte de la facción oposicionista del Gobierno. Al respecto, es importante decir que en muchas ocasiones las razones que motivaban este tipo de fenómenos estaban relacionadas con aspectos ligados a la obtención de la mayor cantidad de beneficios que dependía de situaciones coyunturales como apoyar a la candidatura más fuerte para ostentar el poder en los períodos subsiguientes, tal como se observa con los demás personajes.

Con toda la maquinaria política, presentada anteriormente, construida por el Dr. Antonio González Carazo, éste para el año de 1865 ganó las elecciones y se posesionó como Presidente del Estado Soberano de Bolívar hasta el año 1868.

Tal como mostrabamos al inicio de este aparte, durante el gobierno de Antonio González Carazo se presentaron problemas con respecto al fisco del Estado tal como vimos que ocurrió en el gobierno de Nieto. Con respecto a ello, se publicaba en Barranquilla para Febrero de 1867, es decir terminando el gobierno de Carazo, unas publicaciones sobre unos escándalos en Magangué a propósito de un decreto expedido por el Ciudadano Presidente en curso sobre un impuesto a la industria comercial. La ley promulgada por la Asamblea Legislativa del Estado para Octubre de 1866 estipulaba que dicho impuesto gravaría a "toda persona o compañía, nacional o estranjera que se ocupe de operaciones de comercio dentro del territorio del Estado" ("Lei De impuesto a la industria comercial" Cartagena, 30 de octubre de 1866). Dentro de las disposiciones de la ley se establecía cómo debía ser el pago de la contribución por parte de todas las provincias del Estado de Bolívar y en especial los comerciantes de las ferias de Magangué.

Al respecto, una de las publicaciones de Barranquilla sobre los "Escandalos de Magangue" - fechada en 12 de febrero de 1867- exponía el suscrito "Varios espectadores" que el desorden y caos que se habían presentado en las ferias de Magangue era "la justa resistencia que que la mayor parte de los comerciantes, han 
opuesto a esa ruinosa contribucion con que se ha gravado i restrinjido su poderosa industria". Decía que con ello se buscaba "preparar anticipadamente a la opinion pública de la Nacion i el Estado, para luego vindicar la vergonzosa conducta de nuestro C. Presidente, que a pesar de su guardia pretoriana no pudo restablecer el órden ni dar garantias, dejando de cumplir los deberes legales que se atribuyó"14.

Lo que sucedió fue que durante las ferias de Magangue de ese año, el Presidente del Estado se dirigió a Magangue pues había sido avisado de que los comerciantes de las ferias se habían resistido a pagar la contribución de 33.600 pesos con que fue gravado el distrito en cuestión. Dice el suscrito que el Gobernador de la Provincia se presentó con un "ukase" de 30 hombres armados para obligar por la fuerza a los comerciantes a pagar la contribución correpsondiente. Se dio entonces el enfrentamiento directo entre el pueblo unido de Magangue y los 30 hombres armados del Gobernador. Frente a este hecho, el Presidente pidió al pueblo lo dejasen retirar junto con sus tropas y así fue.

Diríamos entonces que el gobierno del Dr. Carazo no gozó de popularidad como se pensaba, lo cual sería incongruente pues durante la contienda electoral contra Espriella se demostraba que gozaba de la aceptación popular, teniendo en cuenta incluso que "El Partido de la oposición en Barranquilla deseoso de mostrar sus filas, organizó a la Sociedad Democrática el 30 del pasado Octubre y con más de 400 miembros recorrieron la ciudad" (Noticias de Barranquilla, 1864) tal como se afirmaba en una de las publicaciones de 1864 durante la contienda electoral.

Sin embargo, otro pasquín publicado en Barranquilla con fecha de 20 de febrero de 1867 exponía que los acontecimientos ocurrridos en Magangue no habían sido como se habían relatado en la publicación anterior. Todo lo contrario, "la conducta del Presidente en esos acontecimientos no pudo ser mas patriótica" ${ }^{15}$. La presencia de 
este en el distrito de Magangue fue aleatoria pues había comenzado las visitas a todas las provincias del Estado a razón de la culminación de su gobierno; el ukase antes mencionado sólo era un piquete de 30 hombres que desde hacía algunos años se mandaba a todas las ferias de Magangue por solicitud del comercio; que no fue verdad que el Presidente se fugó; que no hubo tal enfrentamiento entre el pueblo y el ejército de los treinta hombres armados sino que fue una "pelea enteramente personal", entre otras aseveraciones que desmentían las expuestas en la publicación anterior.

Esto es muestra de que los problemas presentados en los distintos gobiernos y las polémicas que se generaban alrededor del Gobierno y del Poder Ejecutivo fueron las mismas y de manera constante.

Sin embargo, en el período comprendido entre 1867 y 1868, es decir durante la finalización del período presidencial de Carazo y el comienzo del gobierno del Dr. Manuel Amador Fierro, ocurrieron una serie de eventos que recrudecieron la situación política no sólo del Estado sino también a nivel nacional.

A partir de abril de 1867 se presentó la perturbación completa del régimen constitucional en el Gobierno de la nación, por virtud del decreto sobre orden público que el "Ciudadano Gran Jeneral Presidente de la Union (Tomás Cipriano de Mosquera) expidió con fecha 29 de Abril, declarando la República en estado de guerra, aplicable el artículo 21 de la constitucion i cerradas las sesiones ordinarias del Congreso de 1867'. De esta manera se presentó el rompimiento de las relaciones oficiales con el Congreso y el Presidente de la Unión mandó convocar nuevas elecciones para la conformación de un nuevo Congreso ya que el anterior estaba compuesto de sesenta y ocho miembros liberales y doce conservadores. Esa gran mayoría liberal estaba dividida así: treinta y siete miembros eran favorables a la política del Poder Ejecutivo, y treinta y uno la contrariaban. La liga de estos últimos 
con los doce miembros conservadores, daba mayoría parlamentaria a la minoría liberal del Congreso ${ }^{16}$.

El descontento culminó en "La prision del Ciudadano Presidente de Colombia ejecutada en la madrugada del dia 23 de Mayo, por cuya violencia se ha encargado del Poder Ejecutivo de la Unión el Ciudadano Jeneral Sántos Acosta, como Segundo Designado, en ausencia del primero”. Así pues, ante cuatro de los Ciudadanos Magistrados de la Corte Suprema Federal tomó posesión el Segundo Designado General Santos Acosta del empleo de Presidente de los Estados Unidos de Colombia.

No sólo los hechos del 29 de abril y del 23 de mayo generaron la discordia entre los Estados sino la posesión de Santos Acosta como Presidente de la Unión.

En una publicación titulada "Mensaje del Presidente Constitucional del Estado Soberano de Bolívar a la Asamblea Lejislatiba en sus sesiones estraordinarias de 1867" escribía el Dr. Carazo sobre la reacción que habían tenido alguno de los Estados sobre los hechos presentados y posición al respecto. Entre ellos mencionaba la reacción del Estado del Magdalena la cual se evidenció en que el primer designado de dicho Estado se declaraba en ejercicio del Poder Ejecutivo Nacional "por ser, entre los Presidentes de los Estados, el que ocupa el cuarto lugar para el caso al que se refiere el parágrafo $1^{\circ} \mathrm{del}$ artículo 65 de la Constitucion" y considerando lo anterior mandó nombrar "Secretario para el despacho de los negocios nacionales, prohíbe la libre navegación del rio Magdalena, i manda a poner a su disposición los buques de la marina nacional de guerra" (Mensajes del presidente ..., 1867). Siguiendo con la descripción de la posición de los Estados, describía que la actitud del Estado de Bolívar estaba "honradamente delineada", pero en aquella hoja suelta no se dejaba clara la posición de Bolívar.

16 Este documento fue intitulado "Mensaje del Presidente Constitucional del Estado Soberano de Bolívar a la Asamblea Lejislatiba en sus sesiones estraordinarias de 1867" (Cartagena, junio 15 de 1867) y reposa en la Biblioteca Nacional de Colombia (BNC), Fondo Anselmo Pineda, vol. 978, sin numeración. 
Sin embargo, se escribía en otra publicación por el entonces presidente de la UniónSantos Acosta-en la que expresaba que considerando que el Estado de Bolívar había sido el único de los Estados de la Unión que opuso resistencia a la restauración de la Constitución y de las leyes, obtenida el 23 de mayo de aquel año, se declaraba "la guerra contra el Gobierno del Estado Soberano de Bolívar i contra todos sus ajentes i ausiliares de dentro i fuera del territorio de aquel Estado, con el fin de reducirlo a la obediencia de la Constitucion $i$ de las leyes $i$ al reconocimiento de todos los funcionarios federales para obtener así el restablecimiento del réjimen Constitucional en todo el territorio de la Union"17.

Así pues, se declaró al Estado de Bolívar, en las palabras de un ciudadano del Magdalena, como "esencialmente dictatorialista", es decir a favor del prisionero ex presidente Tomás Cipriano de Mosquera, en contra posición de los demás Estados quienes se asumieron como "constitucionalistas". Lo anterior generó profundos conflictos entre el Estado del Magdalena y el Estado de Bolívar, además que repercutió en la situación política interna del Estado de Bolívar, específicamente en época de elección para Presidente del Estado, lo que veremos más adelante.

Hechos como el asesinato de los señores Bouchart, Murdaugh i Dormin, perpetrado en Cartagena y el aprisionamiento de los ciudadanos M. Vengoechea, jefes, oficiales e individuos de tropa que el gobierno del Magdalena tenía acantonados en el Banco, recrudecieron la agitación política del Estado, pues se denunciaron estos hechos asumiendo como responsable "Ios jefes $i$ oficiales del batallon "Rejenerador" i por otros amigos íntimos del gobierno del señor González Carazo"18.

Como mencionamos anteriormente, el Presidente del Magdalena confiado de que debía ser él el encargado del Poder Ejecutivo Nacional mandó a poner a su

17 Puede consultarse la versión original en "El gobierno Nacional i el Gobierno del Estado Soberano de Bolívar" (Bogotá, a 23 de julio de 1867), Biblioteca Nacional de Colombia (BNC), Fondo Anselmo Pineda, vol. 978, sin número.

18 En una forma de cotejar los sucesos de dos secciones de territorio importantes para los Estados unidos de Colombia en ese momento "Lo que sucede en Bolivar, i lo que tendra que hacer el Magdalena" (Santamarta, 12 de septiembre de 1867), Biblioteca Nacional de Colombia (BNC), Fondo Anselmo Pineda, vol. 978, sin número. 
disposición los buques de la marina nacional de guerra. Lo que ocurrió fue que los señores Bouchart, Murdaugh, Dornin i Smyth eran oficiales del vapor de la mala real "Tyne" y eran portadores de pliegos del gobierno del Magdalena para el presidente de Bolívar. Estos llevaban la comisión de inspeccionar el vapor "Rayo" y hacer un informe sobre el estado del buque para enviarlo al gobierno nacional. Se decía en una hoja suelta que "El crímen de estos desgraciados fué haber tomado el "Colombia" $i$ haberlo puesto a las órdenes del gobierno (...) Las autoridades de Cartajena, que nada hicieron para impedir el crímen, están ahora muertas de miedo, porque temen que el capitan Read sabiendo el hecho quiera vengarlo" (Lo que sucede en Bolívar..., 1867)

Asimismo, sobre los sucesos ocurridos en el Magdalena, Manuel A. Vengoechea comentaba que el día 28 de mayo de 1867 se encontraba su persona en el Banco cuando llegó a aquel puerto la segunda división del ejército y atacó a balazos la pequeña fuerza que tenía allí acantonado el gobierno del Magdalena y tomaron como prisioneros a jefes, oficiales e individuos de tropa y también al suscrito. Este comentaba que "sabía que a la cabeza de esas fuerzas, se hallaban un General que, desde su advenimiento a la Secretaría de Guerra, venía trabajando incansablemente, en la elaboracion del famoso decreto de 29 de Abril, que me era conocido". Al final decía que consignaba en dicho memorial

"la protesta mas solemne i enérjica que hago ante el país, contra el Señor Presidente de Bolívar, por haber convertido esta noble i heróica ciudad, patria de tantos mártires i tantos heroes, i tan justamente llamada redentora, en calabozo de los ciudadanos que han tenido el honor de combatir los primeros la triste i ridícula dictadura del General Mosquera"19.

Así vemos cómo las discordias entre los Estados vecinos y las acciones contra la persona de varios personajes de la política de estos Estados, así como las nuevas asociaciones y alianzas políticas se encontraban enmarcadas en la discusión política 
nacional. Tal como plantea Posada Carbó (1995), las maquinarias políticas locales se conexionan con las nacionales actuando todas ellas en concordancia con las directrices de estas últimas.

Al respecto, de la situación del sr. Vengoechea, el Diputado Jose A. Porras, en nombre de la Asamblea del Estado de Bolívar, decía: "Restitúyase su libertad, por el Ciudadano Presidente del Estado, al Sr. Manuel Vengoechea i demas ciudadanos que le consignó el Sr. Comandante Gral. De Marina i 2 Division". El Diputado asimismo explicaba que estos no eran prisioneros del Estado de Bolívar porque "El Estado de Bolívar no hace la guerra al Estado Soberano del Magdalena" (Al publico, 1867, pza 70).

Sea dicho de paso que, hablando sobre el mismo acontecimiento de la división del país por los hechos del 29 de Abril y los subsecuentes problemas, encontramos una publicación del mismo Diputado José A Porras en el que invita a los ciudadanos de Bolívar que "en vez de separarnos de la "Union Colombiana", unidnos a ella mas estrechamente para combatir al Dictador" y propone que acepten el proyecto de ley que "protesta contra el crímen del 29 de Abril último cometido por el Gran General Tomas C. de Mosquera", proclamando asimismo el reconocimiento como "Gobierno Lejítimo de la República el que representa el Ciudadano General Santos Acosta, quien salvó a la Patria del vilipendio que pesaba sobre ella, con la gloriosa reaccion del 23 de Mayo". (A la Nacion, 1867, pza 71)

Estando así las cosas, las elecciones para Presidente del Estado de Bolívar que se llevaron a cabo en el mes de septiembre, no escaparon a la influencia de la política nacional.

En una hoja suelta escrita por los srs. Manuel Z. de la Espriella y Celso Puentes comentaban que debía hacerse justicia inculpando al responsable de todos los disturbios en el Estado de Bolívar y en general en el país, así como debía defenderse a Santos Acosta de las acusaciones de perjuro y traidor ("una observacion", 1867, pza 73) . Por esto se entiende que los suscritos estaban en contra del ex presidente Mosquera, apoyado por el entonces Presidente del Estado, el Dr. Carazo. Sin 
embargo, exponía el sr. Manuel Z. de la Espriella que "verdad es que los actos repetidos i recientes de desconfianza i animadversion de que hemos sido víctimas los liberales que no somos partidarios de la Administracion del Doctor Antonio González Carazo, llegó a producir, no solo nosotros, sino en todos los miembros del partido liberal, inclusive muchos Caracistas, una indignacion i resentimiento grandes...".

Finalmente, expresaban que "tenemos datos para creer que la Administracion que debe inaugurarse el día $1^{\circ}$ de Octubre próximo, adoptará una política conciliadora i de justicia,20.

Lo anterior es un ejemplo de cómo funcionó el fenómeno de adhesión y retractación de adeptos en las candidaturas para Presidente del Estado que empezaría en 1868.

Según lo registrado, los nombres sobre los cuales se debatía el cargo de Presidente del Estado eran los de Manuel Amador Fierro y Ramón Santo Domingo Vila. Esta contienda electoral tiene elementos claves que dejan entrever cuan dinámica era la política de la época y específicamente en el Estado de Bolívar, ya que Ramón Santo Domingo Vila era amigo del sr. Carazo desde que encabezaron la empresa de la revolución del 59. Asimismo, Manuel Amador Fierro, a pesar de ser "jóven, i como nuevo en la política, estais ajeno de resentimientosi rencores"("posesion del presidente...", sf) tenía excelentes relaciones con el ex presidente Carazo. Sin embargo, los caracistas en su mayoría adoptaron la candidatura de M. Amador Fierro y no la de Ramón Santo Domingo Vila. Asimismo, el primero no sólo contó con los caracistas sino también con los que en otro momento habrían sido opositores de Carazo.

Más interesante aún es que a pesar de que muchas publicaciones denunciaban que la candidatura de Santo Domingo Vila era la candidatura del partido Conservador, éste terminó apoyando en gran medida la candidatura y posterior presidencia del sr. Fierro. 
Así pues, escribía Juan Antonio de la Espriella en una hoja suelta sobre los miembros liberales que votaron por su candidatura en 1864 y decía de ellos que sólo desean la unión del partido, que han olvidado los resentimientos pasados y que

"Ni yo, ni ninguno de esos liberales, se acuerdan ya de tales hechos, sino para procurar que no se repitan (...) Si el Dr. Amador Fierro es el elejido Presidente del Estado para el próximo período constitucional, yo seré el primero en prestarle apoyo eficaz, leal $i$ decidido, i creo que de la misma manera piensan todos los que opinaron en mi favor"21.

Por otro lado, escribían unos caracistas- incluyendo a Manuel González Carazo, hermano del ex presidente Carazo- que "Desde el año de 1864 en que resistimos con nuestra fé i fuerza republicanas la Candidatura del Sr. Juan A. de la Espriella para Presidente del Estado en aquel periodo constitucional, consagramos mancomunadamente nuestras personales simpatías por el modesto e independiente representante del pueblo que en la Asamblea Lejislativa de ese mismo año, justificó con despejada intelijencia e incorruptible firmeza la probidad de sus opiniones políticas" (Diagamos la verdad, 1867, pza 65).

En las anteriores publicaciones se evidencia lo dicho anteriormente, es decir el apoyo claro y contundente de la facción caracista para la candidatura de Fierro así como la de los que en su momento se hicieron llamar espriellistas que eran en gran medida nietistas como ya lo señalamos al comienzo del trabajo.

Además de ello, el candidato Fierro contó con el apoyo de Antonio González Carazo, pues al momento de este entregar el poder a aquél decía: "Es esta la vez primera que aquí se transmite de una manera constitucional la suprema autoridad ejecutiva, i es 
una dicha inmensa para el Estado mismo i para mí, llegar de ese modo al término de mis funciones públicas, dejando a vuestro cargo la direccion i la responsabilidad del Gobierno" (Diagamos la verdad, 1867, pza 65). A lo que Amador respondía:

"Yo os estimo de la manera mas profunda las espresiones de felicitacion que acabais de dirijirme, así como la manifestacion de los patrióticos deseos que os animan respecto de mi gobierno; pero hacedme la justicia de creerlo, motivos de mas elevado carácter, tendré para estimar la cooperacion de nuestras luces como Ciudadano, i la que me ofrecéis de vuestra espada como Jeneral” (Diagamos la verdad, 1867, pza 65)..

Hasta aquí hemos observado que en definitiva las fuerzas liberales del Estado de Bolívar sostenían la candidatura de Fierro. Lo anterior se debía entre otras cosas, a "La alianza íntima i funesta de este Ciudadano (Ramón Santo Domingo Vila) en el actual Congreso de Colombia con los adversarios de la causa federal; los variados datos que poseemos i estamos dispuestos a exhibir de que la Candidatura Santo Domingo está garantizada como el triunfo absoluto del partido Conservador; $i$ sobre todo la constancia que nos asiste de que el gran partido liberal está resuelto a favorecer con su voto al Sr. Manuel Amador Fierro para Presidente del Estado, constituye la resolucion de agregar nuestras firmas i esfuerzos sin vacilacion alguna para sacar triunfante de las urnas electorales al desinteresado patriota" (Diagamos la verdad, 1867, pza 65)., exponían unos liberales en Marzo de 1867.

Ahora bien, el partido liberal en el Estado de Bolívar parece haberse unido para apoyar la candidatura de Fierro. Sin embargo, hay un hecho interesante con respecto al partido conservador para este período. Resulta que este se había estado reuniendo en sus juntas para lograr reorganizarse y lograr recuperar el poder en el Estado nuevamente. Muestra de lo anterior fueron las elecciones de Concejeros Municipales que se llevaron a cabo en diciembre 8 de 1867.

En una hoja suelta se decía que

"El partido Conservador resuelto entrar en una vida activa, lisonjeado por la esperanza de que la nueva Administracion ejecutiva, sea prácticamente republicana $i$ 
que, elevándose, como es de su deber, por encima de las pasiones de la época, sea el Presidente el primer magistrado de los bolivarenses, i no de un partido. Yo no soi siquiera amigo personal del Dr. Amador Fierro; mas abrigo un no sé qué halagador, que me hace aguardar que esa bella ilusion se convierta en realidad".( "al publico", 1865 pza 89)

En un pasquín publicado seis días después de la anterior hoja suelta, expresaba el infrascrito- liberal- que era un hecho que las elecciones verificadas para "Concejeros municipales" habían resultado adversas al partido liberal y que no había nada que hacer más que aceptar el hecho con resignación republicana pues muchos habían sido los liberales que con su apatía e indiferencia habían contribuido al triunfo del partido conservador ("la razon", 1867, pza 90). De hecho, haciendo referencia al transcurrir del día 8 de Diciembre en que se celebraron las elecciones de concejeros municipales, exponían algunos conservadores en una publicación que "el partido Conservador no solo no conspira, sino que, satisfecho de vuestro proceder (del presidente Fierro) del ocho, se ha ofrecido a sí propio sosteneros, hidalgamente, en las crisis que puedan presentárseos en el curso de vuestra administracion..." (al publico, 1867, pza 91).

Sea dicho de paso, que es muy probable que el apoyo del partido conservador a la candidatura de Fierro y su consecuente gobierno presidencial haya tenido relación también con la situación política nacional en tanto que, como se expresaba en una hoja suelta- "El Jeneral Mosquera, el hombre de la escuela absolutista, el refujiado, el asilado del partido liberal, que tocó a nuestras puertas cuando el partido conservador, cansado de sus hechos i de sus doctrinas, pronunció contra él la sentencia terrible del ostracismo-, ese hombre se ha alzado contra la lei creyendo hallar en el partido liberal apoyo firme a sus funestas miras ¿Lo hallará? Imposible!" "Salvemos al Estado, 1867, pza 74). De este modo, siendo el partido conservador contrario a Mosquera para entonces, dicho partido hubiese resuelto apoyar una candidatura que nada tuviera que ver con él como lo fue la del Dr. Fierro. 


\section{Conclusiones}

Habiendo logrado la reconstrucción de las facciones liberales y todo su actuar político podemos concluir que las diferencias de gobiernos no eran sustanciales sino de carácter meramente discursivo, en tanto que tanto Nieto como Carazo y Amador Fierro llevaron a cabo las mismas políticas siendo que en algún momento habían sido opositores de estas.

Los denuestos e injurias por parte de un sector político contra la Administración vigente fueron los mismos en los distintos momentos, en tanto que generalmente se recurrió al argumento de la ilegitimidad del gobierno en curso.

Las fuentes primarias aquí utilizadas como hojas sueltas, pasquines y circulares sirvieron como mecanismos de movilización del electorado en los cuales los actores pudieron expresar libremente sus posiciones políticas generando a través de la opinión pública la creación de maquinarias políticas capaces de derrocar y montar gobiernos.

Asimismo, la capacidad para derrocar y montar gobiernos de dichas facciones fue posible a través del fraude y violencia electorales pues, de esta manera fue fácil la manipulación de los votos y la alteración de los resultados.

El accionar político de las facciones deben analizarse teniendo en cuenta la coyuntura, que a la final son las que determinan la filiación política y de esta manera el comportamiento electoral. 


\section{Referencias.}

Fals Borda, O. (1981) El Presidente Nieto. Historia doble de la costa. Tomo II :Bogotá: Carlos Valencia Editores.

Posada Carbó, E. (1995) "Civilizar las urnas: conflicto y control en las elecciones colombianas, 1830-1930", en Partidos políticos y elecciones en América Latina y la Península Ibérica, 1830-1930, editado Carlos Malamud : Madrid: Instituto Universitario Ortega y Gasset, 145-166.

Melo, J. O. (1995) Colombia Hoy. Perspectivas hacia el siglo XXI. 15 edición aumentada, Bogotá D.C: TM editores. 
Ramírez Bustos, P. (2002) Cultura política y cotidianidad electoral en el Estado de Santander, 1857-1886 (Bogotá: Ministerio de Cultura.

Vanegas Beltrán, M. (2012). Las facciones del Liberalismo en Cartagena: rivalidades y conflictos por el poder, 1930-1945. Anuario de Historia Regional y de las Fronteras, 17 (2), 347-369.

Referencias derivadas de fuentes primarias históricas. (Hojas sueltas, pasquines y hojas circulares)

"A la Nacion" (Cartagena, junio 26 de 1867), Biblioteca Nacional de Colombia (BNC), Fondo Anselmo Pineda, vol. 978, pza. 71.

"A la opinion" (Cartagena, julio 29 de 1867), Biblioteca Nacional de Colombia (BNC), Fondo Anselmo Pineda, vol. 978, pza. 75.

"A los liberales" (Cartagena, 28 de agosto de 1864), BNC, Fondo Anselmo Pineda, vol. 978 pza. 31

"A los liberales" (Cartagena, 4 de agosto de 1864), Biblioteca Nacional de Colombia (BNC), Fondo Anselmo Pineda, vol. 978, pza. 29

"Aclaratoria" (Cartagena, septiembre $1^{\circ}$ de 1864), Biblioteca Nacional de Colombia (BNC), Fondo Anselmo Pineda, vol. 978, pza. 32

"Al Presidente de la Asamblea Lejislativa" (Cartagena, 17 de junio de 1867), Biblioteca Nacional de Colombia (BNC), Fondo Anselmo Pineda, vol. 978 pza. 69.

"Al publico" (Barranquilla, enero 16 de 1865), Biblioteca Nacional de Colombia (BNC), Fondo Anselmo Pineda, vol. 978, pza. 41.

"AL Público" (Cartagena, 12 de diciembre de 1867), Biblioteca Nacional de Colombia (BNC), Fondo Anselmo Pineda, vol. 978, pza. 91. 
"Al Publico" (Cartagena, 23 de junio de 1867), Biblioteca Nacional de Colombia (BNC), Fondo Anselmo Pineda, vol. 978, pza. 70.

"Al Publico", Bibioteca Nacional de Colombia (BNC), Fondo Anselmo Pineda, vol. 978, pza. 89.

"Alocucion del Gobernador de la Provincia, a los habitantes de Cartajena" (Cartagena, 12 de diciembre de 1864), Biblioteca Nacional de Colombia (BNC), Fondo Anselmo Pineda, vol. 978, pza. 40.

"Apelacion a la opinion pública" (Cartagena, diciembre 22 de 1867), Biblioteca Nacional de Colombia (BNC), Fondo Anselmo Pineda, vol. 978, sin numeración.

"Ataque i defensa de garantias individuales" (Cartagena, 16 de mayo de 1864), BNC, Fondo Anselmo Pineda, vol. 938, pza. 26.

"Capítulo en que se demuestra que la superchería está de parte de los gobiernistas, o séase del Presidente del Estado i de su Srio. Jeneral" (Cartagena, 3 de noviembre de 1864), Biblioteca Nacional de Colombia (BNC), Fondo Anselmo Pineda, vol. 978, pza. 36.

"Cual antes, discutamos" (Cartagena, 10 de enero de 1866), Biblioteca Nacional de Colombia (BNC), Fondo Anselmo Pineda, vol. 978, pza. 51.

“Digamos la verdad" (Cartagena, 9 de marzo de 1867), Biblioteca Nacional de Colombia (BNC), Fondo Anselmo Pineda, vol. 978, pza. 65.

"El capitan araña” (Cartagena, enero 8 de 1866), Biblioteca Nacional de Colombia (BNC) , Fondo Ansemo Pineda, vol. 978, pza. 50.

"El Gobierno del Estado fuera de la lei" (Cartagena, 21 de diciembre de 1865), Biblioteca Nacional de Colombia (BNC), Fondo Anselmo Pineda, vol. 938, pza. 44. 
"El gobierno Nacional i el Gobierno del Estado Soberano de Bolívar" (Bogotá, a 23 de julio de 1867), Biblioteca Nacional de Colombia (BNC), Fondo Anselmo Pineda, vol. 978, sin número.

"Escandalos de Magangue" (Barranquilla, 12 de febrero de 1867), Biblioteca Nacional de Colombia (BNC), Fondo Anselmo Pineda, vol. 978, pza 62.

"Jose Araujo Gobernador de Cartajena" (Cartagena, noviembre 4 de 1859), Bbiblioteca Nacional de Colombia (BNC), Fondo Anselmo Pineda, vol. 978, pza. 11.

"La razon" (Cartagena, diciembre 10 de 1867), Biblioteca Nacional de Colombia (BNC), Fondo Anselmo Pineda, vol. 978, pza. 90.

"Lei De impuesto a la industria comercial" (Cartagena, 30 de octubre de 1866), Biblioteca Nacional de Colombia (BNC), Fondo Anselmo Pineda, vol. 978, sin numeración.

"Lo que sucede en Bolivar, i lo que tendra que hacer el Magdalena" (Santamarta, 12 de septiembre de 1867), BNC, Fondo Anselmo Pineda, vol. 978, sin número.

"Los Hechos de Magangué Tal como acontecieron" (Cartagena, febrero 20 de 1867), Biblioteca Nacional de Colombia (BNC), Fondo Anselmo Pineda, vol. 978, pza. 63.

"Manuel Pereira Plata. Coronel de la milicia de Esatdo de Bolívar i Comandante jeneral delos departamentos del Sinú i Corozal" (Chinú, 3 de diciembre de 1859), Biblioteca Nacional de Colombia (BNC), Fondo Anselmo Pineda, vol. 978, pza. 14.

"Mensaje del Presidente Constitucional del Estado Soberano de Bolívar a la Asamblea Lejislatiba en sus sesiones estraordinarias de 1867" (Cartagena, junio 15 de 1867), Biblioteca Nacional de Colombia (BNC), Fondo Anselmo Pineda, vol. 978, sin numeración.

"Noticias de Barranquilla" (Cartagena, noviembre 3 de 1864), Biblioteca Nacional de Colombia (BNC), Fondo Anselmo Pineda, vol. 978, pza. 35. 
"Posesion del Presidente constitucional del Estado de Bolivar", Biblioteca Nacional de Colombia (BNC), Fondo Anselmo Pineda, vol. 978, sin número.

"Protesta" (Cartagena, $1^{\circ}$ de julio de 1867), Biblioteca Nacional de Colombia (BNC), Fondo Anselmo Pineda, vol. 978, pza. 72.

"Salvemos al Estado" (Cartagena, julio 3 de 1867), Biblioteca Nacional de Colombia (BNC), Fondo Anselmo Pineda, vol. 978, pza. 74.

"Una esplicacion conveniente" (Cartagena, 27 de agosto de 1867), Biblioteca Nacional de Colombia (BNC), Fondo Anselmo Pineda, vol. 978, pza. 80.

"Una observacion" (Cartagena, junio 30 de 1867), Biblioteca Nacional de Colombia (BNC), Fondo Anselmo Pineda, vol. 978, pza. 73. 